\title{
Frequency dependency analysis for differential capacitive sensor
}

\author{
Nurul Arfah Che Mustapha, A. H. M. Zahirul Alam, Sheroz Khan, Amelia Wong Azman \\ Department of Electrical and Computer Engineering, International Islamic University Malaysia, Malaysia
}

\begin{tabular}{l}
\hline \hline Article Info \\
\hline Article history: \\
Received Mar 7, 2019 \\
Revised May 3, 2019 \\
Accepted May 27, 2019 \\
\hline Keywords: \\
CVC \\
Differential capacitive sensor \\
Discrete elements \\
Frequency analysis \\
Sensor sensitivity \\
\hline
\end{tabular}

\begin{abstract}
A differential capacitive sensing technique is discussed in this paper. The differential capacitive sensing circuit is making use of a single power supply. The design focus for this paper is on the excitation frequency dependency analysis to the circuit. Theory of the differential capacitive sensor under test is discussed and derivation is elaborated. Simulation results are shown and discussed. Next, results improvement has also been shown in this paper for comparison. Test was carried out using frequency from $40 \mathrm{kHz}$ up to $400 \mathrm{kHz}$. Results have shown output voltage of Vout $=0.07927$ $\mathrm{Cx}+1.25205$ and good linearity of R-squared value 0.99957 at $200 \mathrm{kHz}$. Potential application for this capacitive sensor is to be used for energy harvesting for its potential power supply.
\end{abstract}

Copyright $\odot 2019$ Institute of Advanced Engineering and Science. All rights reserved.

\section{Corresponding Author:}

Nurul Arfah Che Mustapha,

Department of Electrical and Computer Engineering,

International Islamic University Malaysia,

P.O. Box 10, Jalan Gombak, 50728 Kuala Lumpur, Malaysia.

Email: nurularfah@iium.edu.my

\section{INTRODUCTION}

In measurement system, when two conductive materials are arranged in parallel and separated by non-conductive or dielectric element, a charge is stored in the capacitor in terms of electric fields. A typical dielectric material is air, plastic or ceramic and recently, organic solvent has been widely used for Lab-on-Chips, LoC purpose [1]. A common capacitance range used is between $1 \mathrm{pF}$ and $1000 \mu \mathrm{F}$. Depending on the design and method used in the system, capacitance is first converted into voltages and continue its conversion process into desired forms such as frequency, duty cycle, digital and phase.

In CMOS realization for very high speed [2], a switched-capacitor method is best suited for this application, in addition to its immune to stray capacitances [3]. However, it results to moderate resolution due to incapable of handling capacitance changes with frequency higher than $10 \mathrm{~Hz}$ [4]. In Capacitance-tofrequency design, higher resolution is achievable [5]. However, it suffers nonlinearity problem due to poor accuracy at high frequency range [6].

On the other hand, in charge/discharge method, the output voltage is depending on the sampling time [3]. The sampling time of this charge/discharge converter are limited by the measured capacitance value. The larger the capacitance, the larger the charge and discharged time [3]. Other method that used double sensing elements is called differential capacitive sensor method. This method is effective to overcome the previous problems mentioned earlier such as it can cancel parallel stray capacitance at sensor connected cable [7] and it can provide good accuracy even at high frequency of $\mathrm{MHz}$ operation [8].

This paper is about differential capacitive sensor that uses discrete components and has utilized single supply to source to its elements like oscillator, operational amplifiers, voltage divider circuit and instrumentation amplifier. The focus of this paper is to analyse the effect of frequency dependency to the 
differential capacitive circuit. It is the addition study on work done in [9]. The frequency under test is at 200 $\mathrm{kHz}$. Based on the study, the proposed circuit can also work under frequency from $40 \mathrm{kHz}$ up to $400 \mathrm{kHz}$.

\section{FREQUENCY DEPENDENCY TRANSFER FUNCTION}

In a very low differential capacitance sensing circuit where the output voltage of the amplifier is almost at $0 \mathrm{~V}$ voltage level, a proper output voltage could not be obtained when $\Delta C_{x}$ is less than the nominal $C_{x 0}$. This is because it has exceeded the negative side. There is a need to set some reference level higher than $0 \mathrm{~V}$ voltage level at positive side, so that both positive and negative output voltage amplitude of $V_{\text {out }}$, could be observed only at positive side. This can be done by giving an input DC voltage, i.e. the reference voltage, $V_{\text {ref }}$ to the non-inverting input of the Opamp that acts as a voltage level shifter is shown in Figure 1. This Figure 1 is an extracted version of Figure 2 in $[9,10]$. At one side of the differential capacitive sensing, the output voltage of the operational amplifier is:

$$
V_{\text {out }}{ }^{\prime}=\left[1+s C_{x} \frac{R_{f}}{1+s R_{f} C_{f}}\right] V_{r e f}-\left[s C_{x} \frac{R_{f}}{1+s R_{f} C_{f}}\right] V_{e x t}
$$

where the $s$ is corresponding to $j \omega$

Several conditions may exist when the reference voltage, $V_{\text {ref }}$, is supplied to the non-inverting input of the amplifier. Based on (1), the output voltage is divided into several conditions as the following:

\section{Case I: Vref $=0$}

$$
\left|\frac{V_{\text {out }}}{V_{\text {ext }}}\right|=-s C_{x} \frac{R_{f}}{1+s R_{f} C_{f}}
$$

\section{Case II: Vref=Vext}

$$
\left|\frac{V_{\text {out }}}{V_{\text {ext }}}\right|=1
$$

Case III: Vref $<$ Vext when Vref $=(1-\mathrm{m})$ Vext where $(0<\mathrm{m}<1)$

$$
\left|\frac{V_{\text {out }}}{V_{\text {ext }}}\right|=1-\left(1+s C_{x} \frac{R_{f}}{1+s R_{f} C_{f}}\right) m
$$

\section{Case IV: Vref $>$ Vext when Vref=nVext where $(\mathbf{n}>1)$}

$$
\left|\frac{V_{\text {out }}}{V_{\text {ext }}}\right|=n\left(1+s C_{x} \frac{R_{f}}{1+s R_{f} C_{f}}\right)-s C_{x} \frac{R_{f}}{1+s R_{f} C_{f}}
$$

where $m$ and $n$ are the excitation input voltage, $V_{\text {ext }}$ multiplier numbers which is equal to $n V_{\text {ext }}$. or $(1-m) V_{\text {ext }}$ 


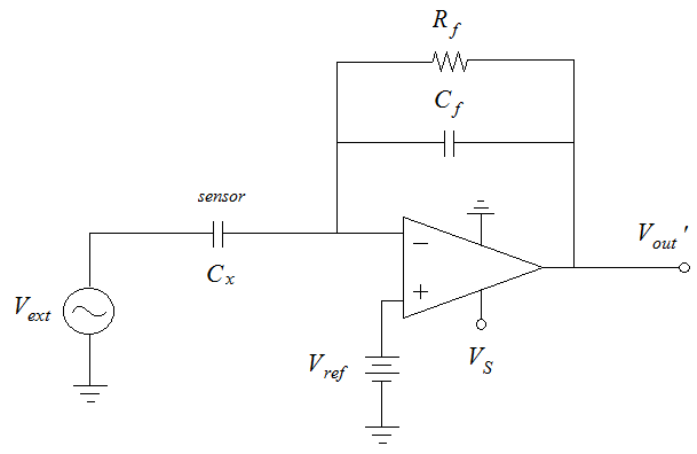

Figure 1. Vref at non-inverting differential amplifier input as level shifter

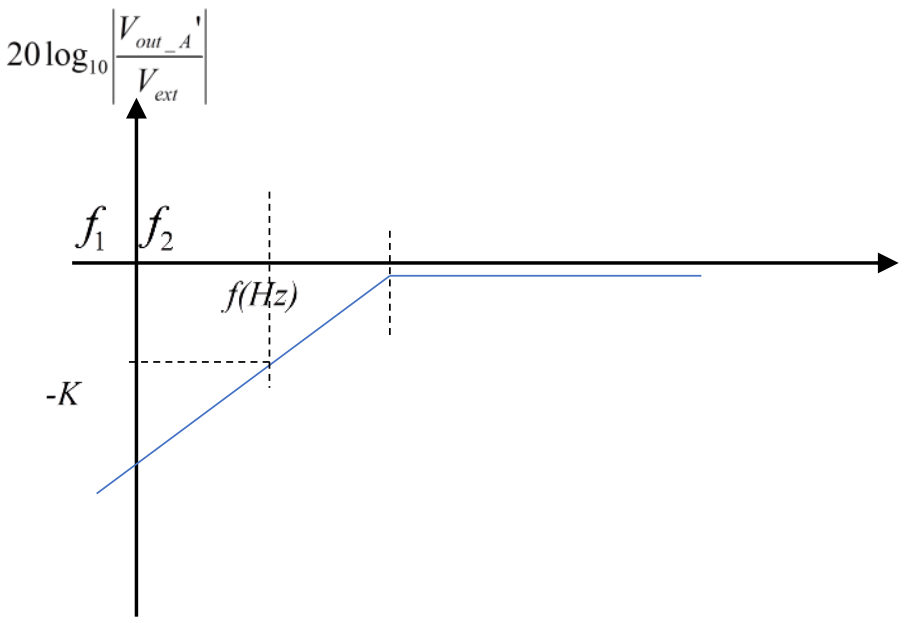

Figure 2. Estimated bode plot for transfer function at opamp a output

Referring to the Figure 2 of $[9,10]$, the design begins by deriving the transfer function opamp $A$ output to the input, $V_{e x t}$, by setting the range of frequency to pass the signal. A continuous supply of $3.3 \mathrm{~V}$ is provided to the circuit and voltage divider is used to level the output voltage to half of supply voltage, which in this case is $1.65 \mathrm{~V}$. The reason is to set the signal in positive range. An excitation supply voltage in terms of sinusoidal waveform, $V_{e x t} \cos \left(2 \pi f_{e x t} t+\varphi\right)$ is used. The test starts with analysis without parasitic impedance to the differential Capacitance-to-Voltage Converter (CVC) circuit. Without the parasitic impedance, the transfer function derivation of the cutoff frequency amplifiers output, $V_{\text {out_ } A}$ ' (refer to Figure 2 of $[9,10])$ at opamp A output is:

$$
\frac{V_{o u t_{-} A}{ }^{\prime}}{V_{\text {ext }}}=-\frac{s R_{f} C_{x}}{1+s R_{f} C_{f}}=-\frac{R_{f} C_{x}}{R_{f} C_{f}} \frac{s}{1+\frac{s}{\left(R_{f} C_{f}\right)^{-1}}}=K f_{1} \frac{s}{1+f_{2} s}
$$

where

$$
\begin{aligned}
& K=-\frac{C_{x}}{C_{f}} \\
& f_{1}=1 \\
& f_{2}=\frac{1}{R_{f} C_{f}}
\end{aligned}
$$

Note that the apostrophe (') sign is a punctuation mark to signal the condition without parasitic capacitance and resistance present in the circuit whereas Figure 2 of $[9,10]$ does not showing this sign. Estimated bode plot theory of opamp A output is sketched as in Figure 2. The straight line is pictured as in 
Figure 1 if only if the corner frequency $f_{2}$ is small and near to frequency $f_{1}$, else the magnitude is at positive side and the $20 \mathrm{~dB} / \mathrm{dec}$ line will crosses $0 \mathrm{~dB}$. The extended derivation of [11] for both amplifiers output transfer function is as in the following:

$$
\begin{aligned}
& V_{\text {out_A }}{ }^{\prime}=-\left(\frac{\left(C_{x}+\Delta C\right)}{C_{f}} \cos 2 \pi f_{\text {sensor }} t\right) V_{\text {ext }} \cos 2 \pi f_{\text {ext }} t \\
& V_{\text {out_B }}{ }^{\prime}=-\left(\frac{C_{r}}{C_{f}}\right) V_{\text {ext }} \cos 2 \pi f_{\text {ext }} t
\end{aligned}
$$

Accordingly, the transfer function taken at $V_{\text {filterA }}$ ' and $V_{\text {filter }}{ }^{\prime}[9,10]$ using the first case (Case I: $\left.V_{r e f}=0\right)$ of (2). $C_{r}$ is a reference capacitor with value equal to nominal value $C_{x 0}$

$$
V_{\text {out }}{ }^{\prime}=G\left[\left(\frac{C_{r}}{C_{f}}-\frac{\left(C_{x}+\Delta C\right)}{C_{f}} \cos 2 \pi f_{\text {sensor }} t\right) \hat{V_{\text {ext }}}-V_{\text {diode } e_{-}{ }^{\prime}}+V_{\text {diode } B}{ }^{\prime}\right]
$$

When $V_{S}=3.3 \mathrm{~V}$ and $V_{e x t}=400 \mathrm{mV}, V_{\text {ref }}$ will be half of $V_{S}$, and it is calculated that the $n$ to be equal to 4.125. For (Case IV: $V_{r e f}>V_{e x t}$ ) when $V_{r e f}=4.125 V_{e x t}$ from (5) it is derived that the output is as in (10)-(11).

$$
\left|\frac{V_{\text {out }}^{\prime}}{V_{\text {ext }}}\right|=4.125\left(1+s C_{x} \frac{R_{f}}{1+s R_{f} C_{f}}\right)-s C_{x} \frac{R_{f}}{1+s R_{f} C_{f}}
$$

And

$$
\frac{V_{\text {out_A } A \text { Vref }>\text { Vext })^{\prime}}}{V_{\text {ext }}}=4.125+3.125 \frac{R_{f} C_{x}}{R_{f} C_{f}} \frac{s}{1+\frac{s}{\left(R_{f} C_{f}\right)^{-1}}}
$$

where

$$
\begin{aligned}
& K=\frac{C_{x}}{C_{f}} \\
& f_{1}=1 \\
& f_{2}=\frac{1}{R_{f} C_{f}}
\end{aligned}
$$

$\hat{V_{e x t}}$ is the excitation amplitude voltage after demodulation (i.e. $\hat{V_{e x t}}=400 \mathrm{mV}$ ). Since the same Schottky diode is used for the circuit, the different between both diode voltage is only slightly different caused by changes in $C_{x}$ (i.e: the difference is $\pm 0.1 \mathrm{pF}$ ), for simplification both as $V_{\text {diodeA }}{ }^{\prime}=V_{\text {diodeB }}$ ' is set equal. The final output voltage is:

$$
V_{\text {out }(\text { Vref }>\text { Vext })}{ }^{\prime}=G\left[3.125 \hat{V}_{\text {ext }}\left[\frac{\left(C_{x}+\Delta C\right)}{C_{f}} \cos 2 \pi f_{\text {sensor }} t-\frac{C_{r}}{C_{f}}\right]\right]
$$

The relevance of this equation is, when there is no capacitance change in $\Delta C_{x}$, there is no movement at the sensor so, $f_{\text {sensor }}=0$ and when both $C_{r}$ and $C_{x}$ at nominal capacitance value $C_{x 0}=5 \mathrm{pF}$, the resulted output voltage $V_{\text {out }}=0$. The gain $G$ need to be within the limit and not exceeding the $+V_{D D}$ for the relevance output value as in $[12,13]$. 


\section{OPAMP TRANSFER FUNCTION DEPENDENCY TO THE EXCITATION FREQUENCY RESULTS AND ANALYSIS}

In this test, the frequency dependency is investigated by varying the frequency from $1 \mathrm{kHz}$ to 10 $\mathrm{GHz}$, with voltage amplitude of $400 \mathrm{mV}$ is kept constant. The resulted bode plot is verified by checking the dependency of excitation frequency to the derived transfer function. For (2) of Case I: $V_{\text {ref }}=0$, using $C_{f}=C_{x}=C_{r}=C_{x 0}=5 \mathrm{pF}$ and $R_{f}=10 \mathrm{M} \Omega$. Simulation result of Figure 3 has shown almost to the estimated theoretical value (6) and expected corner frequency $B$, is $3.183 \mathrm{kHz}$.

Figure 4(a) shows the effect of changing in reference capacitance, $C_{f}$ to the magnitude of operation across frequencies at the final output. The feedback resistor, $R_{f}$, at this point is set to $10 \mathrm{M} \Omega$. Changing of $C_{f}$ value has caused magnitude shift to the passband frequencies. While changing the value of $R_{f}$ has affected to magnitude shifting in the final output of the whole circuit as shown in Figure 4(b). Effect of changing in reference resistance, $R_{f}$ at the feedback loop to the frequencies of operation when $C_{f}$ is set to $5 \mathrm{pF}$.

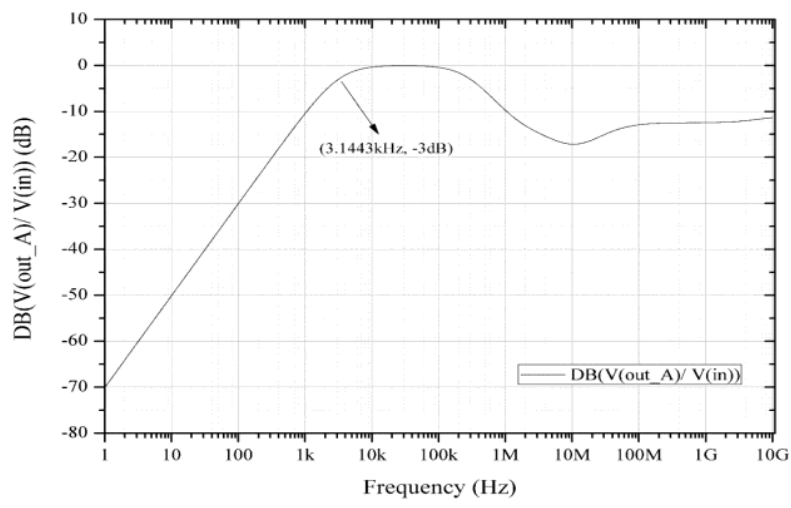

Figure 3. Simulated magnitude result at opamp a output

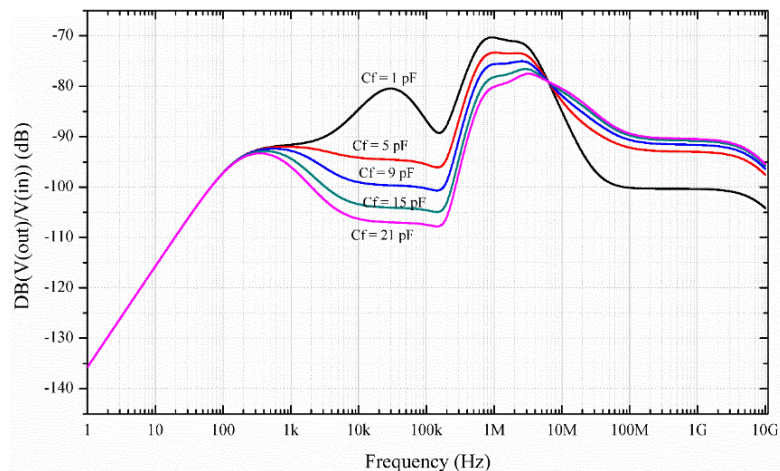

(a)

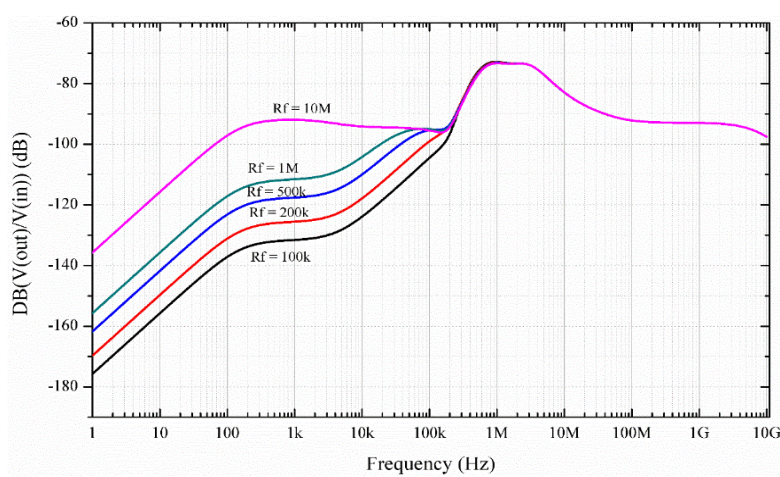

(b)

Figure 4. Effect of changing, (a) reference capacitance, $C_{f}$ (b) reference resistance, $R_{f}$ to the magnitude across frequencies 


\subsection{Before improvement of capacitance detection change, $\Delta C_{x}$}

The overall output voltage linearity graph is plotted in Figure 5 when frequency is at $200 \mathrm{kHz}$ and simulation is using $R_{f}=10 \mathrm{M} \Omega, R_{d}=100 \mathrm{k} \Omega$ and $C_{d}=0.1 \mu \mathrm{F}$. The $200 \mathrm{kHz}$ frequency was chosen to test the possibilities and condition of the differential amplifier when running at frequency higher than $100 \mathrm{kHz}$. When frequency goes higher than $100 \mathrm{kHz}$, which is shown in Figure 5, less points of detection were observed and the sensitivity is low. By rules, the $f_{-3 d B}$ should be low than the cutoff frequency $\left(f_{c}=3.18 \mathrm{kHz}\right.$, refer to the bode plot of Figure 2). In this case has satisfied the condition when using $R_{d}=100 \mathrm{k} \Omega$ and $C_{d}=0.1 \mu \mathrm{F}$, the $f$. $3 d B=15.9 \mathrm{~Hz}$.

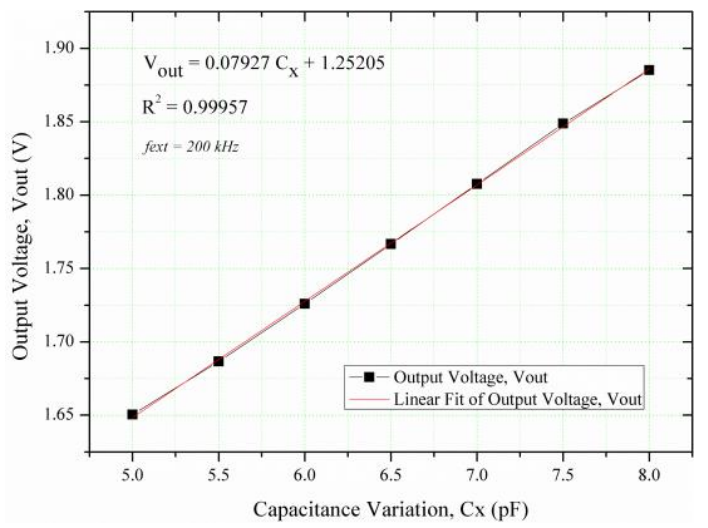

Figure 5. Effect of output voltage with $C_{x}$ variation for $R_{d}=100 \mathrm{k} \Omega$ and $C_{d}=0.1 \mu \mathrm{F}$ using $V_{s}=3.3 \mathrm{~V}$ at $200 \mathrm{kHz}$

Improvement on the number of detection points across certain capacitance range is increased by increasing the bandwidth of the low pass filter. This is by decreasing the $R_{d}$ value and $C_{d}$ value of the components. Figure 6 shows the simulation results using low $R_{d}$ and $C_{d}$ values of $10 \mathrm{k} \Omega$ and $0.01 \mu \mathrm{F}$ respectively, with $R_{f}=10 \mathrm{M} \Omega$. In this case, the cutoff frequency, $f_{-3 d B}=1.59 \mathrm{kHz}$, which satisfy the condition less than cutoff frequency $f_{c}=3.183 \mathrm{kHz}$.

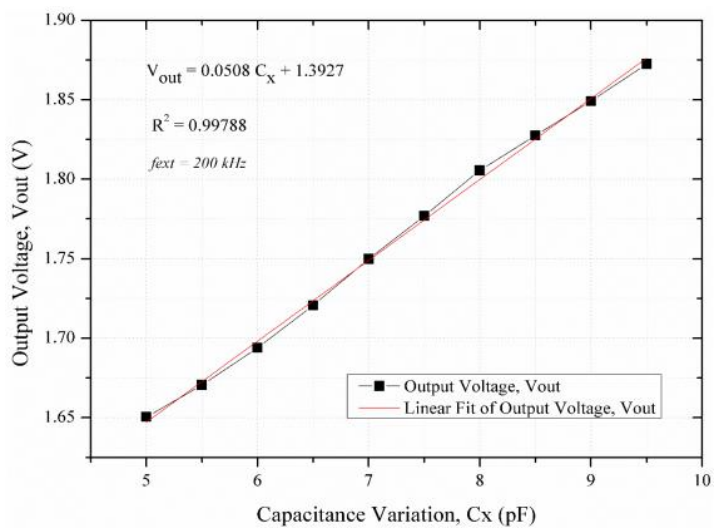

Figure 6. Effect of output voltage with $C_{x}$ variation for $R_{d}=10 \mathrm{k} \Omega$ and $C_{d}=0.01 \mu \mathrm{F}$ using $V_{s}=3.3 \mathrm{~V}$ at $200 \mathrm{kHz}$

\subsection{After improvement of capacitance detection change, $\Delta C_{x}$}

Improvement is made to the capacitance change, $\Delta C_{x}$ so that wider capacitance range is been detected with low detection change at high frequency. This is done by using the $R_{f}$ selection method. This method is considered relevant due to diode current value at higher frequency (i.e: $200 \mathrm{kHz}$ ) is becoming stable regardless of the change of the $R_{f}$ value (refer to diode current of Figure 4.10 for $R_{d}=10 \mathrm{k} \Omega$ and $\left.C_{d}=0.01 \mu \mathrm{F}\right)$. Same principle applied to any components value at higher frequency, such as when $R_{d}=10 \mathrm{k} \Omega$ and $C_{d}=0.1 \mu \mathrm{F}$ of Figure 2 of [14]. 
Figure 7 shows the linearity result using $\Delta C_{x}=0.1 \mathrm{pF}$ change with $R_{d}=10 \mathrm{k} \Omega$ and $C_{d}=0.1 \mu \mathrm{F}$. Different $R_{f}$ has been selected to overcome the sensitivity problems where Figure 7 is at $R_{f}=10 \mathrm{M} \Omega$ at $f_{e x t}=200 \mathrm{kHz}$. These values must satisfy the condition $>f_{-3 d B}$ range. In this case the frequencies are $3.183 \mathrm{kHz}$, $159 \mathrm{kHz}$ and $106 \mathrm{kHz}$ respectively, when $f_{-3 d B}=159.13 \mathrm{~Hz}$. At high frequency, high sensitivity of capacitive change of detection is achieved by reducing the value of the feedback resistor $R_{f}$ and other results of different analysis can also be found in [15].

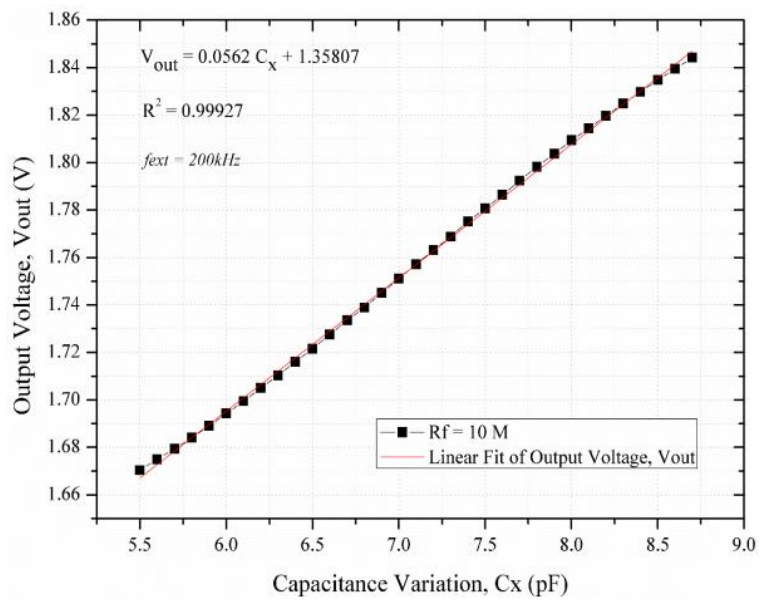

Figure 7. Corrected capacitance change, $\Delta C_{x}=0.1 \mathrm{pF}$ with $R_{f}=10 \mathrm{M} \Omega$ at $f_{\text {ext }}=200 \mathrm{kHz}$

\section{CONCLUSION}

In summary, this paper presented a differential capacitive sensing with output voltage of $V_{\text {out }}=0.07927 C_{x}+1.25205$ with R-squared value of 0.99957 at frequency $200 \mathrm{kHz}$. Using nominal capacitance of $5 \mathrm{pF}$ and $R_{f}=10 \mathrm{M} \Omega$, simulation result has shown almost to the estimated theoretical value and expected corner frequency of $3.183 \mathrm{kHz}$. The change of $C_{f}$ value has caused magnitude shift to the passband frequencies. While changing the value of $R_{f}$ has affected to magnitude shifting in the final output of the whole circuit. In future, a proposed solution can be done to improve points of detection of output voltage capacitance sensing across frequencies, by properly setting the values of component involved such as the resistance and capacitance of the differential capacitive sensing.

\section{ACKNOWLEDGEMENTS}

This work is funded by the Research Initiative Grant Scheme (RIGS)-2018 (Ref: IIUM/504/G/14/3/1/1/RIGS17-023-0598) by the Research Management Centre, International Islamic University Malaysia

\section{REFERENCES}

[1] E. Ghafar-zadeh and M. Sawan, "CMOS Capacitive Sensors for Lab-on-Chip Applications," Springer, 2010. doi:10.1007/978-90-481-3727-5

[2] S. A. Mohammed, H. Dogan \& M. T. Ozgun, "An 85\%-efficiency reconfigurable multiphase switched capacitor DC-DC converter utilizing frequency, switch size, and interleaving scaling techniques," Microelectronics Journal, vol. 67, 2017, pp. 155-161. doi:10.1016/j.mejo.2017.08.004

[3] Á. Pintér and I. Dénes, "Interface circuit for measuring small capacitance changes in sensor networks," IET Science, Measurement \& Technology, vol. 9, no. 5, pp. 570-578, 2015. doi:10.1049/iet-smt.2014.0221

[4] M. R. Haider, M. R. Mahfouz, S. K. Islam, S. A. Eliza, W. Qu \& E. Pritchard, "A low-power capacitance measurement circuit with high resolution and high degree of linearity," 2008 51st Midwest Symposium on Circuits and Systems, 2008, pp. 261-264. doi:10.1109/MWSCAS.2008.4616786

[5] V. Matko and M. Milanović, "Temperature-compensated capacitance-frequency converter with high resolution," Sensors and Actuators, A: Physical, vol. 220, pp. 262-269, 2014. doi:10.1016/j.sna.2014.09.022

[6] D. Y. Shin, H. Lee \& S. Kim, "Improving the accuracy of capacitance-to-frequency converter by accumulating residual charges," IEEE Transactions on Instrumentation and Measurement, vol. 60, no. 12, pp. 3950-3955, 2011. doi:10.1109/TIM.2011.2147650 
[7] D. M. G. Preethichandra \& K. Shida, "A simple interface circuit to measure very small capacitance changes in capacitive sensors," IEEE Transactions on Instrumentation and Measurement, vol. 50, no. 6, pp. 1583-1586, 2001. doi:10.1109/19.982949

[8] G. Sarkar, A. Rakshit, A. Chatterjee \& K. Bhattacharya, "Low value capacitance measurement system with adjustable lead capacitance compensation, vol. 7, no. 1, pp. 63-70, 2013.

[9] N. A. C. Mustapha, A. H. M. Z. Alam, S. Khan and A. W. Azman, "Single supply differential capacitive sensor with energy harvester compatibility," in 2016 IEEE Industrial Electronics and Applications Conference (IEACon), Kota Kinabalu, 2016, pp. 323-329. doi: 10.1109/IEACON.2016.8067399

[10] N. A. C. Mustapha, A. H. M. Z. Alam, S. Khan and A. W. Azman, "Efficient capacitance sensing for wireless health monitoring systems," IIUM Engineering Journal, vol. 17, no. 2, pp. 21-29, 2016.

[11] N. A. C. Mustapha, A. H. M. Z. Alam, S. Khan and A. W. Azman, "Analysis of the Frequency Dependency to the Single Supply Differential Capacitive Sensor," in the 7th International Conference on Computer and Communication Engineering (ICCCE), 2018, pp. 441-444, 2018.

[12] A. H. M. Z. Alam, N. A. C. Mustapha, N. S. A. A. Hassan, M. R. Islam, S. Khan, A. W. Azman and M. A. Eusuf, "Wireless Structural Health Monitoring System by Capacitor Sensing Technique," IAENG Transactions on Engineering Sciences. pp. 168-178, 2017.

[13] A. H. M. Z. Alam, N. S. A. A. Hassan, N. A. C. Mustapha, M. R. Islam, S. Khan and M. A. Eusuf, "Wireless Capacitor Sensing for Structural Health Monitor," Lecture notes in Engineering and Computer Sciences world Congress on Engineering, pp. 319-321, 2016.

[14] N. A. Che Mustapha, A. H. M. Z. Alam, S. Khan and A. W. Azman, "Current behavior analysis of the single supply differential capacitive sensing," 2016 IEEE Student Conference on Research and Development (SCOReD), Kuala Lumpur, 2016, pp. 1-6.

[15] N. A. C. Mustapha, A. H. M. Z. Alam, S. Khan and A. W. Azman, "Single Supply Differential Capacitive Sensor with Parasitic Capacitance and Resistance Consideration," 2018 7th International Conference on Computer and Communication Engineering (ICCCE), Kuala Lumpur, 2018, pp. 445-448.

\section{BIOGRAPHIES OF AUTHORS}

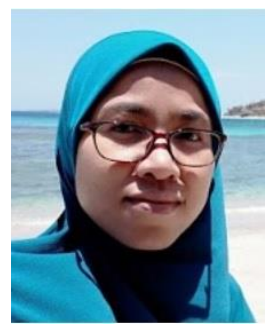

Nurul Arfah Che Mustapha received the B. Eng. Electronics-Computer and Information Engineering and M. Sc. (Electronics Engineering) from the International Islamic University Malaysia (IIUM), Malaysia in 2008 and 2011, respectively. She obtained her Ph.D. degree in Electronics Engineering from IIUM in 2017. She was a graduate research assistant from 20092016 and received IIUM Fellowship from 2011-2015 for her Ph.D degree. Currently, Nurul Arfah works as a Asst. Prof. at the Electrical and Computer Engineering Department, Kulliyyah of Engineering, International Islamic University Malaysia (IIUM). Her research interest is in CMOS, VLSI circuit design, Energy Harvesting and Wireless Sensor Networks, and signal processing of capacitive sensor. Nurul Arfah is also a graduate member of the Instituition of Engineers Malaysia since March 2018 and Member of Institute of Electrical and Electronic Engineers (IEEE), M'18, since early 2018 .

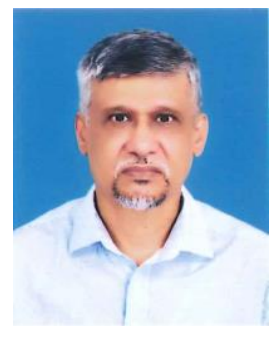

AHM Zahirul Alam works as a Professor at Department of Electrical and Computer Engineering, International Islamic University Malaysia. Prof. AHM Zahirul Alam received his Doctorate of Eng. at Kanazawa University, Japan in March 1996. He did his M.Sc. Engg. in Electrical and Electronic Engineering and B.Sc. Engg. Electrical and Electronic Engineering, in Bangladesh University of Engineering and Technology (BUET) in Bangladesh, both on July 1987 and August 1984, respectively. His research interest is in Solid state devices modeling and characterizations, Microelectronic circuit design, VLSI circuit design, RF CMOS and RF MEMS, Antenna design, Energy Harvesting and Wireless Sensor Networks, Fabrication processes and material characterizations by XRD, FTIR, Raman Spectroscopy, AFM, TEM/SEM. AHM Zahirul Alam also a Chartered Engineer member of Engineering Council, UK on Nov 2016. Other professional background includes: Life Fellow of Institution of Engineers, Bangladesh (IEB, Bangladesh), since 2006, Life Fellow, Bangladesh Computer Society, since 2005, Senior Member of Institute of Electrical and Electronic Engineers (IEEE), M'90, SM'06 (Sept 23, 2006), Member of Institution of Engineering and Technology, IET since December 2015, Member of Institute of Electronics, Information and Communication Engineers, IEICE, Japan, since 2007, Member of International Association of Engineers, IAENG since 2016, Member of IEEE Electronic Devices Society, Member of IEEE Instrument and Measurement Society and Founder Member of Bangladesh Electronics Society since 1999. 


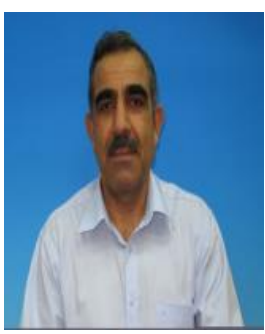

Sheroz Khan received the B.Sc. degree in Electrical and Electronic Engineering from the N-W.F.P University of Engineering and Technology (NWFP UET), Peshawar, Pakistan. He obtained MSc degree in Microelectronic \& Computer Engineering in 1990 from the University of Surrey, UK. $\mathrm{He}$ obtained $\mathrm{PhD}$ in Electrical Engineering in 1994 from University of Strathclyde, UK. He remained a faculty member within the department of Electrical and Electronic Engineering at the NWFP UET Peshawar until December 1999 until he joined UNITEN as a Principal Lecture in January 2000. He is senior member of the IEEE and ahs his research interests in power electronics, instrumentation and measurement, smart interfaces and biomedical electronics engineering. He has authored two books and over 100 articles in journals and in the IEEE Proceedings. Dr. Sheroz Khan also a Chartered Engineer member of Engineering Council, UK.

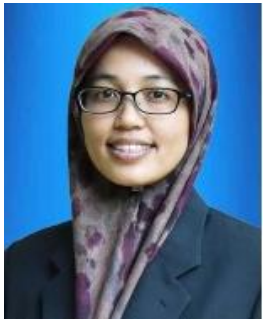

Amelia Wong Azman (M'06) received the B. Eng. Electronics from the University of Southampton, United Kingdom in 2004 and a Ph.D. degree in 2011 from the University of Queensland, Australia. She was a graduate research assistant for the National ICT Australia (NICTA) from 2006-2010 working with a team on smart surveillance project. Currently she is a lecturer in the Electrical and Computer Engineering Department, Faculty of Engineering, International Islamic University Malaysia (IIUM). Her research works are mostly in the area of VLSI design, signal processing and rehabilitation engineering. 